\title{
Bio-manufacturing technology based on diatom micro- and nanostructure
}

\author{
ZHANG DeYuan ${ }^{\dagger *}$, WANG Yu ${ }^{\dagger *}$, CAI Jun, PAN JunFeng, JIANG XingGang \& \\ JIANG YongGang
}

Bionics and Biologic Micro/nano-bio-manufacturing Research Center, Beihang University, Beijing 100191, China

Received March 31, 2012; accepted May 21, 2012

\begin{abstract}
Diatom frustules, considered as novel bio-functional materials, display a diversity of patterns and unique micro- and nanostructures which may be useful in many areas of application. Existing devices directly use the original structure of the biosilica frustules, limiting their function and structural scale. Current research into the shapes, materials and structural properties of frustules are considered; a series of frustule processing methods including structure processing, material modification, bonding and assembly techniques are reviewed and discussed. The aim is to improve the function of diatom frustules allowing them to meet the design requirements of different types of micro devices. In addition, the importance of the comprehensive use of diatom processing methods in device research is discussed using biosensors and solar cells as examples, and the potential of bio-manufacturing technology based on diatom frustules is examined.
\end{abstract}

diatoms, biosilica structure, biomimetics, assembly, microfluidic, micro- and nanomanufacturing, micro device

Citation: Zhang D Y, Wang Y, Cai J, et al. Bio-manufacturing technology based on diatom micro- and nanostructure. Chin Sci Bull, 2012, 57: 3836-3849, doi: $10.1007 / \mathrm{s} 11434-012-5410-\mathrm{x}$

Nature presents a wide range of functional structures. Particularly at the micro- and nanoscale, the complexity and functionality of biological structures are far greater than those of equivalent artificial devices, making these biological structures an appropriate subject for biotechnology and bio-manufacturing [1,2]. In our previous studies, we have reported bio-limited forming [3] and bio-replication forming $[4,5]$ methods for manufacturing functional particles or surface morphology from biological structures. Micro devices with highly desirable structure and characteristics could be produced from biological micro- or nanostructures. Single-celled diatoms are widely distributed in rivers, lakes and other water bodies, and have a fast (exponential) reproductive rate. The cell wall of a diatom known as the frustule, has a transparent structure composed of amorphous silica [6]. The frustule has good mechanical strength $[7,8]$, a variety

$\dagger$ These authors contributed equally to this work.

*Corresponding authors (email: zhangdy@buaa.edu.cn; hutter2@163.com) of three-dimensional (3D) shapes [9,10], multi-level nanopores and microstructures [11,12], large surface area and unique optical properties [13-15], making it a potential novel functional material for bio-manufacturing. Studies on theoretical understanding, manufacturing methods and functionalization of diatom frustules are ongoing.

In the last two centuries, the importance of diatom frustules in the field of micro- and nanotechnology has become increasingly evident. The potential of frustules has been extensively explored by academics and for commercial application. The resulting new theories and techniques have found wide application, leading to the formation of a new interdisciplinary area of research called diatom-based bio-nanotechnology (or diatom nanotechnology) [16-21]. The potential for diatoms in device applications, such as high-sensitivity gas sensors [22], drug delivery devices [23], biocarriers for biosensors [24-27], micro-filters [12,28], solar cells, battery electrodes and electroluminescent display devices [19] has been examined. However, the direct 
use of original frustules limits the function of any practical diatom based device. For example, diatom-based drug delivery devices and filters only work with particles of certain size, limiting the functionality to the available size of the frustule nanopores; diatom-based biosensing devices (gas detectors or biodetection carriers) lack improved arranging or bonding techniques, limiting detection stability and throughput. Recently reported processing methods for structure and material modification, bonding and assembly of diatom frustules may improve frustule functionality to meet the design requirements of micro devices.

In this review, the shape, structure and material properties of frustules are examined as well as existing methods for frustule processing, bonding and assembly. These are discussed to suggest ways to improve the function of frustule based devices. The development of diatom-based biomanufacturing technology will lead to improvement in the efficiency of use of biological resources. The following topics will not be discussed as key points, including molecular biology [28,29], frustule formation [6,30], micromachining [16], diatom nanotechnology (microfluidic/optical application and functional materials $[17,21,31])$, biosensing and biomimetic membranes [18], solar cells, battery, electroluminescent devices [19], gasoline extraction [32], environmental monitoring [33] and phytolith nanotechnology [34]; excellent reviews on these topics are available.

\section{Structure of diatom frustule}

\subsection{Classification of frustule shape}

There are about 110000 species of diatoms, and their frustules show a variety of 3D shapes [35]. To guide the selection of a diatom for a particular device application, the diatom frustules may be classified into three categories according to shape.

The reference coordinate axes are defined as follows (Figure 1): The plane of the valve surface is defined as $x, y$ plane; the major axis of the valve is $X$ and the minor axis of the valve is $Y$ (for pennates only; for centricae: $X=Y$ ); the valve-through axis is $z$-axis, and the length of the line connecting the centers of epivalve and hypovalve is $Z$. Frustules come in three shapes, rod shaped (when $Z>3 X / 3 Y$ for centricae diatoms, or $X>3 Y>3 Z$ for pinnate diatoms), flake shaped (when $X>3 Z$ and $Y>3 Z$, most of which are valves collected from diatom frustules) and a generic 3D shape (when $X \approx Y \approx Z$ ). Figure 1 illustrates some examples of frustules (or valves) shapes.

The three shapes may give different properties in device application or processing. First, devices have varying requirements of the diatom structure. For example, flake shaped frustules/valves are better biocarriers for optical biodetection, because confocal scanning demands that all the antibodies are bound in a plane (see section 3.1). Second, the processing method should match the diatom structure.
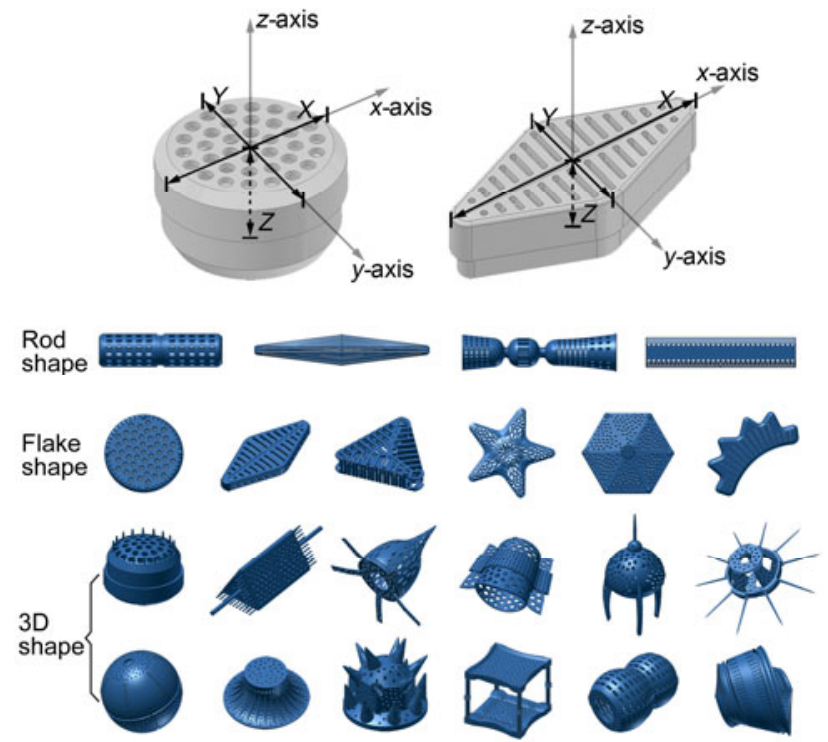

Figure 1 (Color online) Shape classification of diatom frustules. The images are 3D models. For images of actual cells and frustules refer to $[9,10,20,35]$. The actual sizes of the frustules are about $10-80 \mu \mathrm{m}$.

Rod shaped frustules are more fragile (especially pennates) than other shapes, so they should be fixed before processing. However, rod shapes may have advantage in ease of assembling, and the monolayer assembled from rods has larger area coverage rate (or fill rate). Flake shaped frustules/ valves (such as valve of Coscinodiscus sp.) are used more frequently in optical devices, filters and biosensing. One reason is that the multi-level pores of frustules are arranged in a two-dimensional (2D) plane, facilitating the exploitation of their optical properties and filtration functionality. The second reason is that the flat surface of flake shaped frustules allows them to be fixed onto a substrate/device more easily and firmly (the work described in section 2.3 and 2.4 uses this shape). 3D shaped frustules have higher porosity when stacked or assembled, and so can be processed more uniformly (see methods of material modification in section 2.2).

The size of the frustule is another parameter relating to processing. For example, small frustules can be arranged by more methods, and are more affected by Van der Waals forces and particle Brownian motion; big frustules sink faster in still water. Diatom frustules come in a size range of $2 \mu \mathrm{m}$ to $5 \mathrm{~mm}$; however, the size of the frustule does not relate to the species of diatom. For example, the diatom Coscinodiscus sp. has about 500 species, but their cells and frustules have sizes ranging from $10 \mu \mathrm{m}$ to $2 \mathrm{~mm}$. Very few species of diatom have cell sizes less than $5 \mu \mathrm{m}$ and are generally distributed in fresh water; few species have cell sizes greater than $100 \mu \mathrm{m}$ and are generally distributed in sea water. Species with cell sizes in the range 5-100 $\mu \mathrm{m}$ account for more than $60 \%$ of extant diatoms, distributed widely in fresh and seawater, and have a variety of shapes. China has vast water resources spanning a large range of 
latitude, and thus has rich sources of diatoms.

\subsection{Material properties of diatom frustules}

The frustule is generated by the transformation of silicate in the aquatic environment into a hard shell composed of silica (a biomineralization process [31,36,37]). The frustule shows good transmittance in ultraviolet to infrared range, and transmits more than $90 \%$ of visible light. The frustule has physical and chemical properties similar to quartz glass, and a density of $2.1-2.3 \mathrm{~kg} / \mathrm{m}^{3}$. Hamm et al. [7] performed simulation studies of stress distribution in frustules via finite element analysis, and tested the compressive strength of four types of typical diatoms using a glass needle. The results show that the compressive strength of valve and girdle band (pennate diatom) could reach 680 and $330 \mathrm{MPa}$, respectively, and the Young's modulus of a typical frustule is about $22.4 \mathrm{GPa}$. Losic et al. [8] tested the hardness and elastic modulus of two types of frustules using atomic force microscopy (AFM) and found that the cribellum, cribrum and girdles have different mechanical properties, and the elastic modulus of frustule is similar to that of porous silicon manufactured by anodic oxidation. Umemura et al. [38] found that the structure and pores deform after heating at $800^{\circ} \mathrm{C}$ for $2 \mathrm{~h}$. The frustule reacts with hydrofluoric acid and strong alkali $[39,40]$, and thus it is compatible with silicon processing technology, such as wet etching, LIGA micromachining and silicon bonding [41,42].

\subsection{Diatom frustule structure}

Although there are a considerable variety of diatom frustules, their structures do show some common characteristics. As shown in Figure 2, the main structure of a diatom frustule comprises the petri-dish-like epitheca and hypotheca [16], which usually split during the fissiparity period. The new epitheca and hypotheca will separately combine with the original hypotheca and epitheca to form the frustules of the two daughter cells [10]. The epitheca or hypotheca is composed of valve, mantle and girdle band. The valve and girdle band could be easily split by acid washing. In addition, frustules have many micro- or nanoscale substructures [10], such as multilevel pores, marginal processes, spines,

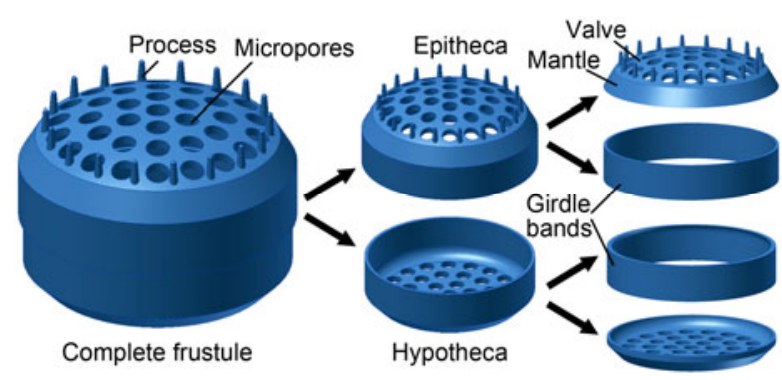

Figure 2 (Color online) Structure of diatom frustules (centricae diatom). and raphe.

The multilevel pores are the main substructures. Figure 3(a) shows typical Coscinodiscus pores [8,12]: hundreds of large pores (called foramen, Figure 3(b)) are regularly arrayed on one side of the frustules; a circular or hexagonal chamber (called an areola) lies under the foramen; scores of second-level pores (blind holes, diameter $200 \mathrm{~nm}$ ) are located at the bottom of the areolae; and numerous sieve pores (diameter $40 \mathrm{~nm}$, Figure 3(c)) are distributed within each second-level pore. The mantle and girdle band of Coscinodiscus also have myriads of pores (diameter $100 \mathrm{~nm}$; Figure 3(d)). Particularly, the pores arranged on the girdle have an asymmetric pore structure, affecting the Brownian motion of mesoscale particles [43]. The center process, satellite process and septa of some diatom frustules may also have micro- or nano-scale pores [10].

Some frustules are not isolated units but are connected with each other through a microstructure of valves. Some types of diatom cells form clusters for migration and to withstand water flow. Figure 4 shows various patterns of clusters, see [10] for more examples. A rational use of these natural communities could simplify the assemblage of frustules for device use. However, the cluster needs careful fixing onto the substrate, because the adjacent frustules may disconnect after the organic matter is removed.

\section{Processing of diatom frustules}

Acid-cleaned frustules contain several components, including
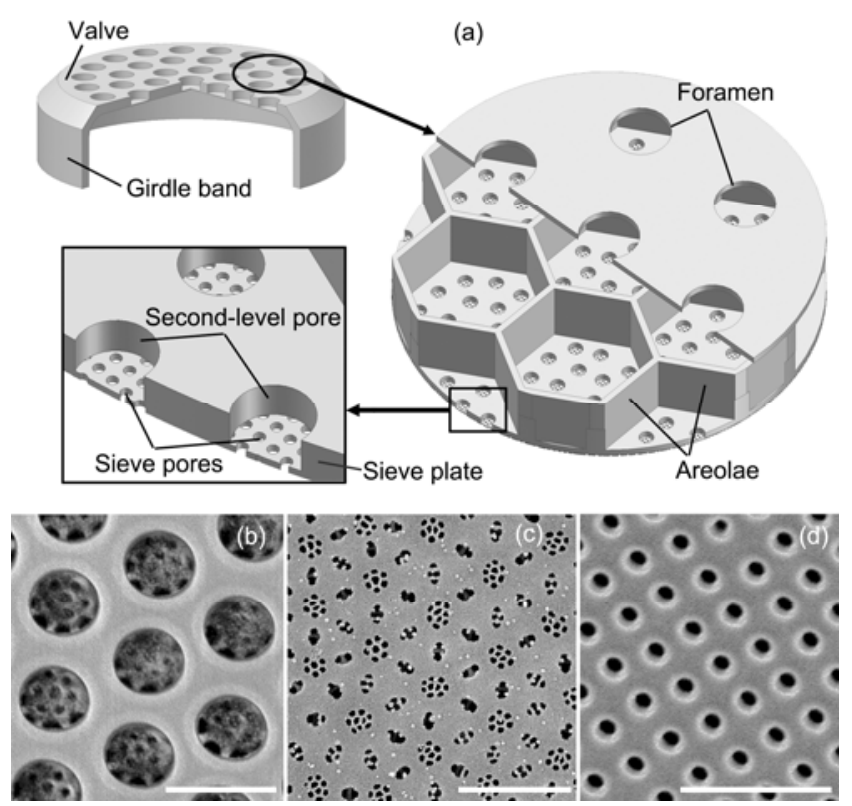

Figure 3 (Color online) Typical structure of multilevel pores (Coscinodiscus sp.). (a) 3D model; (b) arrays of foramen and second-level pores, scale bar $1 \mu \mathrm{m}$; (c) array of sieve pores, scale bar $2 \mu \mathrm{m}$; (d) array of nanopores on girdle band, scale bar $1 \mu \mathrm{m}$. 


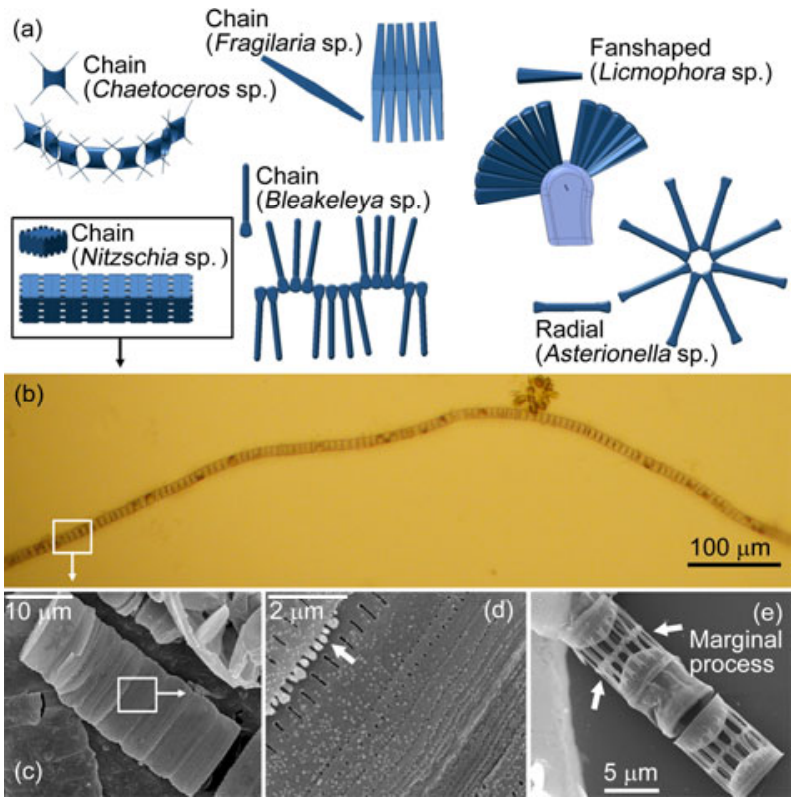

Figure 4 (Color online) Clusters of living diatom cells. (a) Models of diatom clusters; (b) a chain cluster composed of more than one hundred of Nitzschia cells (light microscope image); (c) a chain cluster of Nitzschia cells fixed by $2.5 \%$ glutaraldehyde; (d) microstructure of valves for connecting adjacent frustules of Nitzschia; (e) frustules of Skeletonema sp. connected by marginal processes. (c)-(e) are SEM images.

the complete frustule, valve, girdle band, and divided process, which all should be separated before use or further processing. The valves and girdles have similar diameter and quantity, and thus can hardly be separated using a filter cloth. Our lab (Bionic and Micro/Nano/Bio Manufacturing Technology Research Center of Beihang University) calculated the settling velocity of valve and girdle band of diatom Coscinodiscus sp. (diameter $40 \mu \mathrm{m}$ ) in still-water using Stokes formula, and found both to have different settling velocity due to their different section area [44]. This results was verified experimentally: after stirring and settling for 20 min, $80 \%$ quantity of valves settled to the bottom of the measuring cylinder $(20 \mathrm{~cm}$ in liquid depth), while $80 \%$ quantity of girdles was still distributed in the liquid layer of $10-50 \mathrm{~mL}$ scale (Figure 5(a)). Thus, a method of cycled settling and liquid removal as depicted in Figure 5(b) could be used to separate the valves (collected from the bottom of the cylinder; Figure 5(c)) and girdles (collected from the supernatant of the cylinder; Figure 5(d)).

Using this method, different micro- and nanoscaled components were separated and collected from many varieties of diatoms [45]. It was found that particles with dimensions of several microns settled more slowly than those with dimensions of dozens of microns, and thus substructures separated from the frustules can be collected relatively easily. An advantage of the settling method is that the impact load of still-water exerted on the frustules is less than that by filtration, making the settling method ideal for industrial production compared with filter cloth or gas phase separation.
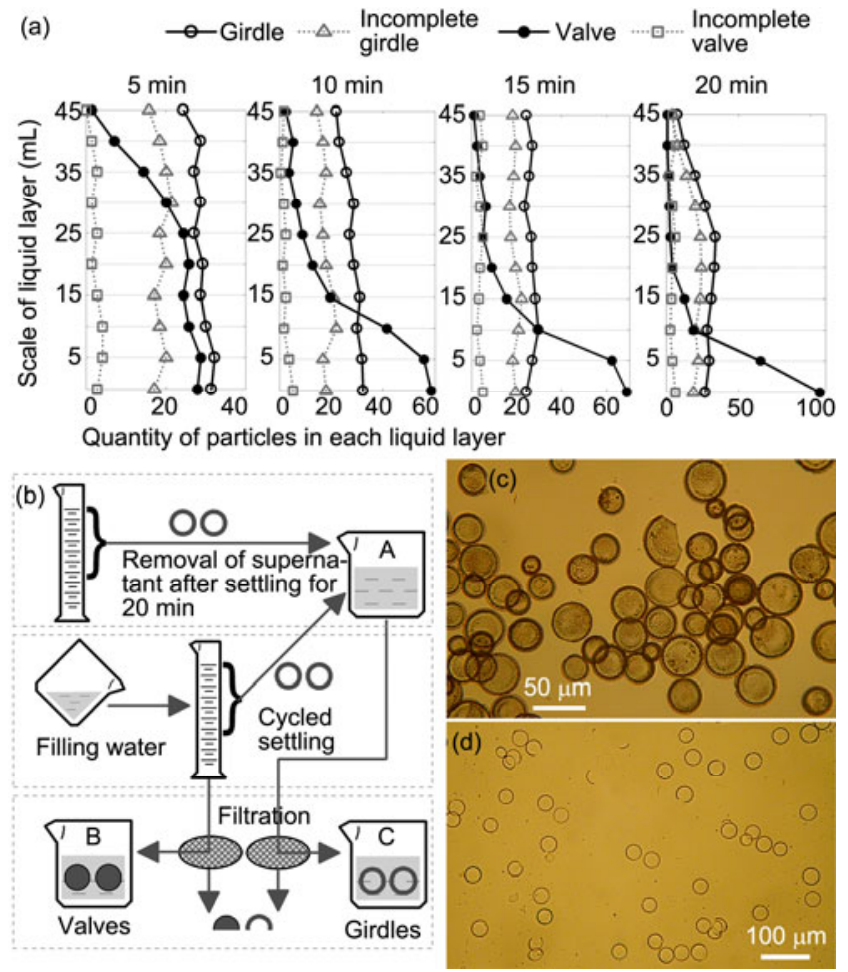

Figure 5 (Color online) Settling separation of valves and girdles of diatom Coscinodiscus sp. (a) Quantity of valves and girdles on each liquid layer; (b) schematic of settling separation method; (c) valves and (d) girdles collected (light microscope images).

\subsection{Structural modification of diatom frustule}

Most diatom frustules are thinner than a human hair (the diameter of adult human hair is about $70-100 \mu \mathrm{m}$ ), and thus their structure is difficult to modify using traditional micromachining methods. This problem could be addressed by two strategies: a chemical method based on the material of frustule, and a culture method based on the growth and reproduction methods of the diatom.

(i) Chemical method. Certain surface deposition processes based on $\mathrm{SiO}_{2}$ could be used to thicken the frustule or reduce its pore size. In a study by Losic et al. [46], the technique of atomic layer deposition (ALD) was used, in which ultrathin films of $\mathrm{TiO}_{2}$ are deposited uniformly on the frustules to reduce their pore size and to increase the selectivity of particle size when using frustules for filtration. At $100^{\circ} \mathrm{C}$, the frustules were ventilated using a sequence of gases: $\mathrm{TiCl}_{4}(0.4 \mathrm{~s}), \mathrm{N}_{2}(0.5 \mathrm{~s}), \mathrm{H}_{2} \mathrm{O}(0.5 \mathrm{~s})$ and $\mathrm{N}_{2}(0.5 \mathrm{~s})$. Every cycle of the sequence increases the thickness of $\mathrm{TiO}_{2}$ film by $0.04 \mathrm{~nm}$ (see eq. (1)). The size of sieve pores may be reduced from 43 to $5 \mathrm{~nm}$ by repeated cycles (between 1 to 1000 times). The ALD technique can also be used to deposit other materials onto the frustule, such as $\mathrm{Al}_{2} \mathrm{O}_{3}, \mathrm{ZrO}_{2}$, $\mathrm{SnO}_{2}, \mathrm{~V}_{2} \mathrm{O}_{5}, \mathrm{ZnO}$ and $\mathrm{TiN}$ [46].

Alternatively, frustules are soluble in hydrofluoric acid (HF) and strong alkali solutions (eqs. (2) and (3)). We used HF to etch the frustules to enlarging the pores and reducing 
the frustule thickness [39]. Due to the multilevel pore structure of Coscinodiscus sp., etching will result in a discontinuous change of pore size, which should be observable in filtration applications. Figure 6(a) shows the cross section of an areola, in which the sieve pores play the role of the filtration pore. The surface layer of frustule requires more time to dissolve, and can thus be considered to act as a resist layer. Figure 6(b) shows how filtration pores change during $\mathrm{HF}$ etching. After the first stage, the diameter of the sieve pore had increased from 40 to $60 \mathrm{~nm}$, and then adjacent sieve pores began to interconnect; the filtration pores were about 60-200 $\mu \mathrm{m}$ and became uncontrollable until the cribellum dissolved completely. In the second stage, the secondlevel pores act as filtration pores and their size is increased from 200 to $300 \mathrm{~nm}$, and then adjacent 2nd-level pores begin to connect; the filtration pores were about 300-700 $\mu \mathrm{m}$ and became uncontrollable again, and the cribrum dissolved.
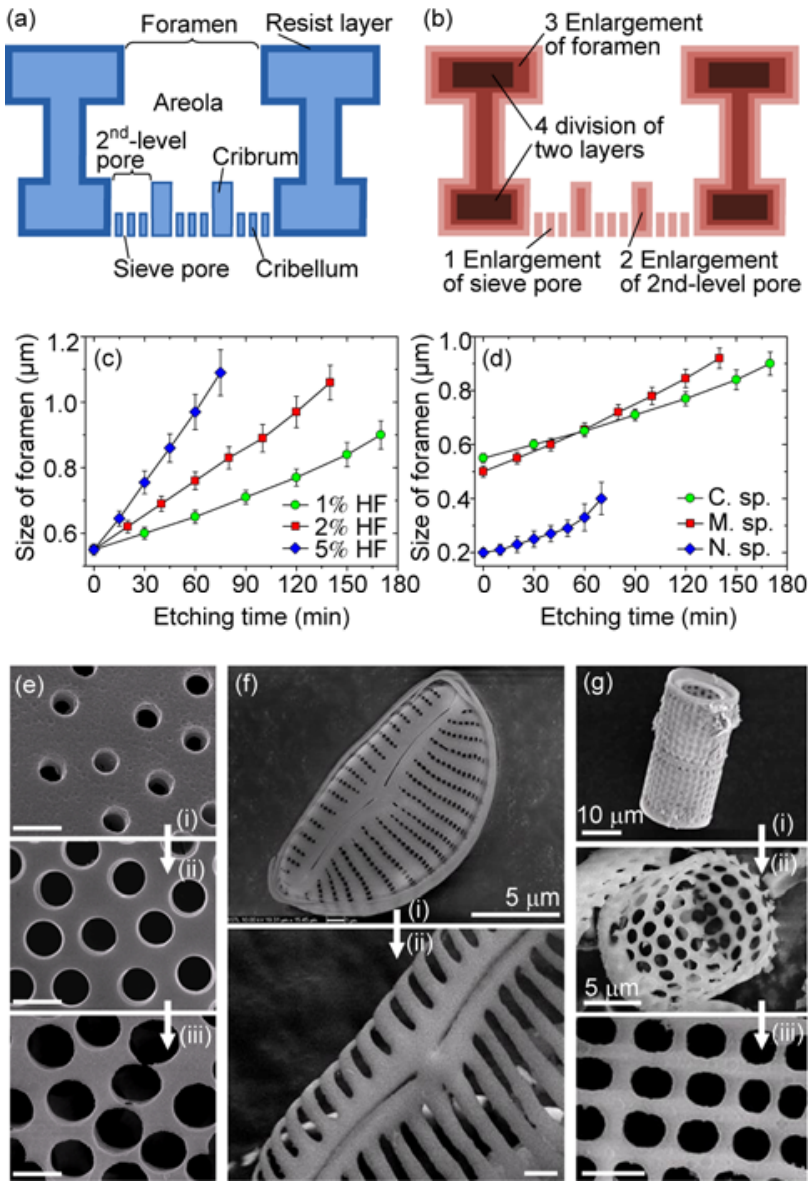

Figure 6 (Color online) Enlargement of pores using HF as etchant. (a) Schematic model of areolae (cross-section); (b) structural modification caused by HF etching; (c) enlargement of foramen by different concentration of HF; (d) enlargement of foramen of different diatoms by $1 \% \mathrm{HF}$; (e)-(f) frustule samples processed by $1 \% \mathrm{HF}$ solution for foramen enlargement: (e) foramen of Coscinodiscus (C. sp.): (i) original, (ii) $1 \mathrm{~h}$, and (iii) $3 \mathrm{~h}$; (f) foramen of Navicula (N. sp.): (i) original, (ii) $1 \mathrm{~h}$; (g) foramen of Melosira (M. sp.): (i) original, (ii) $3 \mathrm{~h}$, and (iii) $3.5 \mathrm{~h}$. Unlabelled scale bars: $1 \mu \mathrm{m}$. (e) $-(\mathrm{g})$ are SEM images.
At the third stage, the foramen plays the role of filtration pore, and the diameter is increased from 700 to about 1100 $\mathrm{nm}$ (the dissolution of septa supporting areola will divide the valve into two plates at this stage), and then adjacent foramen connect and the valve became incomplete. Therefore, the adjustable size ranges of the filtration pores of Coscinodiscus sp. are (40-60 nm), (200-300 nm), and $(700-1100 \mathrm{~nm})$. When using the valve as filter, the filtration pore can be adjusted in this span to suit the size of the particles.

As shown in Figure 6(c) and (d), the sizes of the foramen are increased after etching with $1 \%$ HF for $1-3 \mathrm{~h}$ (Figure $6(\mathrm{e})-(\mathrm{g})$ are SEM images of diatom samples). However, the cribellum will fully dissolve in $1 \% \mathrm{HF}$ in 5 min. Thus $0.1 \%$ $\mathrm{HF}$ is the proper etchant for enlarging the sieve pores. HF was not found to affect the composition, chemical bonds, or photoluminescence signature of diatom frustules but could reduce their surface area (the surface area of Melosira frustules reduced from 75 to $14 \mathrm{~m}^{2} / \mathrm{g}$ in $5 \mathrm{~min}$ by $1 \% \mathrm{HF}$ ), implying that the sieve pores contribute to at least $60 \%$ of surface area.

Crawford et al. [40,47] used $\mathrm{NaOH}$ mixture $(1 \% \mathrm{NaOH}$, $2 \% \mathrm{NaOCl}, 1 \%$ sodium dodecyl sulfate and $50 \mathrm{mmol} / \mathrm{L}$ sodium dodecyl sulfate) to etch the frustules and observed that the inner structure of frustule is loose and porous (24-48 h is needed to remove the surface resist layer). Compared with baking [38] and alkali etching, HF etching is a faster and cleaner method for pore enlargement and structure modification.

$$
\begin{gathered}
\mathrm{TiCl}_{4}+2 \mathrm{H}_{2} \mathrm{O}=\mathrm{TiO}_{2}+4 \mathrm{HCl} \\
\mathrm{SiO}_{2}+2 \mathrm{NaOH}=\mathrm{Na}_{2} \mathrm{SiO}_{3}+\mathrm{H}_{2} \mathrm{O} \\
\mathrm{SiO}_{2}+4 \mathrm{HF}=\mathrm{SiF}_{4} \uparrow+2 \mathrm{H}_{2} \mathrm{O}
\end{gathered}
$$

(ii) Structural modification based on the natural methods of frustule formation: the formation of frustules in diatom cells is a bottom-up process. The formation process of the frustule structure is briefly discussed here; for full details see $[6,17,30]$. As shown in Figure $7(\mathrm{a})$, water-soluble silicic acid $\left(\mathrm{Si}(\mathrm{OH})_{4}\right)$ in the environment passes through the sieve pores and cytomembrane (composed of a pectic substance) and enters into the diatom cell. Then, $\mathrm{Si}(\mathrm{OH})_{4}$ is transported by silica transport vesicles (STV) to reach the silica deposition vesicles (SDV) where valves are produced [48]. The silanol groups of adjacent $\mathrm{Si}(\mathrm{OH})_{4}$ are hydrolyzed in SDV and form Si-O-Si bonds [49]. The "silaffins" protein and long chain polyamines (LCPA) in SDV catalyze the hydrolysis reaction and affect the patterns of the valves [50-52]. The formation of valves occurs in two stages (see pennates and centricae in Figure 7(a)): at first, along with the widening of SDV, the framework structure is formed. This stage usually takes few to several minutes. At the next stage, the valve becomes thickened as does the SDV, and microstructures develop on the valve. The second stage 

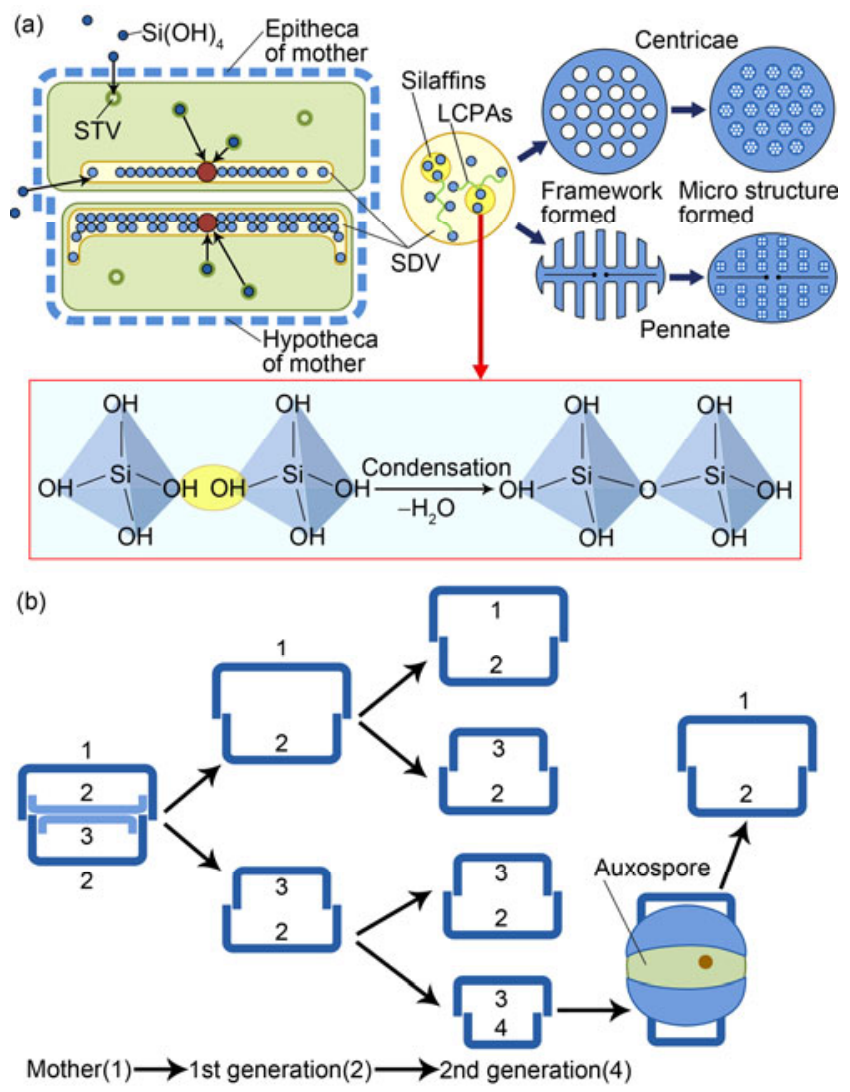

Figure 7 (Color online) Schematic illustrations of (a) formation and (b) reproduction of diatom frustules. (a) was revised after consideration of $[17,19,31]$.

usually takes several hours. The structure changes greatly during its formation, and thus different structures of the valve could be obtained by acid-washing the cells at different stages. Moreover, the formation of frustule can be affected by the mother liquor in SDV, such as $\mathrm{H}^{+}$[53], salt [54] and metal ions [55,56]. In another study, Jeffryes et al. $[56,57]$ added $50 \mu \mathrm{mol} / \mathrm{L}$ of $\mathrm{Ge}(\mathrm{OH})_{4}$ to the culture medium, which reduced the pore size of the newly generated frustules from 203 to $124 \mathrm{~nm}$, and a frustule framework structure was obtained. The $\mathrm{GeO}_{2}-\mathrm{SiO}_{2}$ composite frustule has special semiconducting and photoelectric characteristics, namely its photoluminescence (PL) intensity was enhanced by four fold. Townley et al. [55] observed that the pore size of diatoms in nickel sulfate-polluted seawater was altered, and the PL of polluted frustule vanished. This lesson from nature may help us improve the culture medium for fast cultivation of diatoms or modifications to frustules. For example, the nutrient profile of a lake during an algal bloom disaster may help us optimize the medium for fast cultivation of certain species of diatom. In addition, the protein and enzyme content in diatom cells was altered by Poulson et al. [58] using molecular genetic methods to modify the structure or properties of a diatom from its roots.

(iii) Structural modification in the frustule reproduction method: diatoms reproduce mainly by fissiparity, which leads to fast reproduction, exponential growth and reduced frustule size. As shown in Figure 7(b), the epitheca and hypotheca of the mother cell are of different sizes (labelled as 1 and 2); the newly formed "half-thecas" in SDV are slightly smaller than 1 and 2 (labeled as 2 and 3). After the first division, the two daughter cells have frustules composed of 1-2 and 2-3 separately. After the second division, four daughter cells are produced, whose frustules are composed of 1-2, 2-3 (two) and 3-4 separately. Every act of division reduces the size of frustule by dozens of nanometers but the pore size does not change. When the size of a cell reduces to below two-thirds of the biggest cell, that cell will restore to the original size by auxospore formation. Using the size decline law, frustules of certain size can be obtained by measuring the reproductive duration. We have attempted to cultivate diatoms in a polydimethylsiloxane (PDMS) microfluidic chip. The reproduction speed in the PDMS chip was reduced even as new medium was injected into the culturing pool using a micro injector (the size of culturing pool should be larger than $500 \times 500 \times 20 \mu \mathrm{m}^{3}$ to keep the cells alive). However, there are several advantages in using a chip culture. First, the growth and reproduction of diatom could be observed more easily in such small space than in a petri-dish or 96-hole cell culture plate. Second, the inner environment of chip is cleaner and the condition of culture could be easily adjusted. Third, special frustule structures can be obtained by injecting $90^{\circ} \mathrm{C}_{2} \mathrm{O}_{2}$ into the culturing pool to remove the organic matter (living cells), such as the framework structure of developmental valves in the SDV and frustules of a certain size after several reproduction cycles.

(iv) Degeneration of diatoms in an artificial medium can be used as another approach to structural modification. Certain species of diatom show a reduction in cell size after years of cultivation in the laboratory, and other species even generate variant structures. For example, the triadius structure of Phaeodactylum tricomutum changes into a rhomboid structure after cultivating for several years under laboratory conditions (found by the Freshwater Algae Culture Collection of the Institute of Hydrobiology (FACHB) Collection of Wuhan, China). We propose two possible reasons for this: first, although the artificial culture medium can simulate all the nutrient substances available in natural waters, the diatoms grown in the laboratory lack certain necessary challenges to survival such as aquatic bacteria (some diatoms grow and reproduce faster when challenged by certain aquatic bacteria), upper food chain predators, severe environmental stress and other factors present in natural waters. Lack of these survival stimulations may weaken the physiological functions of diatom cells. Second, the small volume of the culture flask or incubator may restrain the generation of auxospores.

One disadvantage of the culture method is that it requires weeks to months to accomplish significant structural modifications. 


\subsection{Material modification of diatom frustule}

Material modification is an important approach for changing the material property or function of frustules. Current research suggests several new materials to add or replace in frustules by chemical, culture or replica method while keeping the original structure of frustules. These methods are summarized in several reviews, including in a review by Losic et al. [21] (Figure 8 was revised on the basis of [21]).

(i) Direct processing of frustules. Sandhage et al. [59-66] use the term Bioclastic and Shape-Preserving Inorganic Conversion (BaSIC) methods to describe their method for modifying the biosilica frustule into new nanocrystal materials whilst maintaining the original frustule structure. Through gas/silica displacement reactions (e.g. magnesio-isothermic reduction), $\mathrm{MgO}$ [59], $\mathrm{TiO}_{2}$ [60] and $\mathrm{Si}$ [61], frustules with fine nanoscale structures were obtained. The technological conditions of fabricating frustules composed of other materials, such as $\mathrm{Al}_{2} \mathrm{O}_{3}, \mathrm{CaO}, \mathrm{Fe}_{2} \mathrm{O}_{3}, \mathrm{Li}_{2} \mathrm{O}, \mathrm{Nb}_{2} \mathrm{O}_{5}, \mathrm{SrO}$ and $\mathrm{Ta}_{2} \mathrm{O}_{5}$ have been established [62]. Subsequent coating or

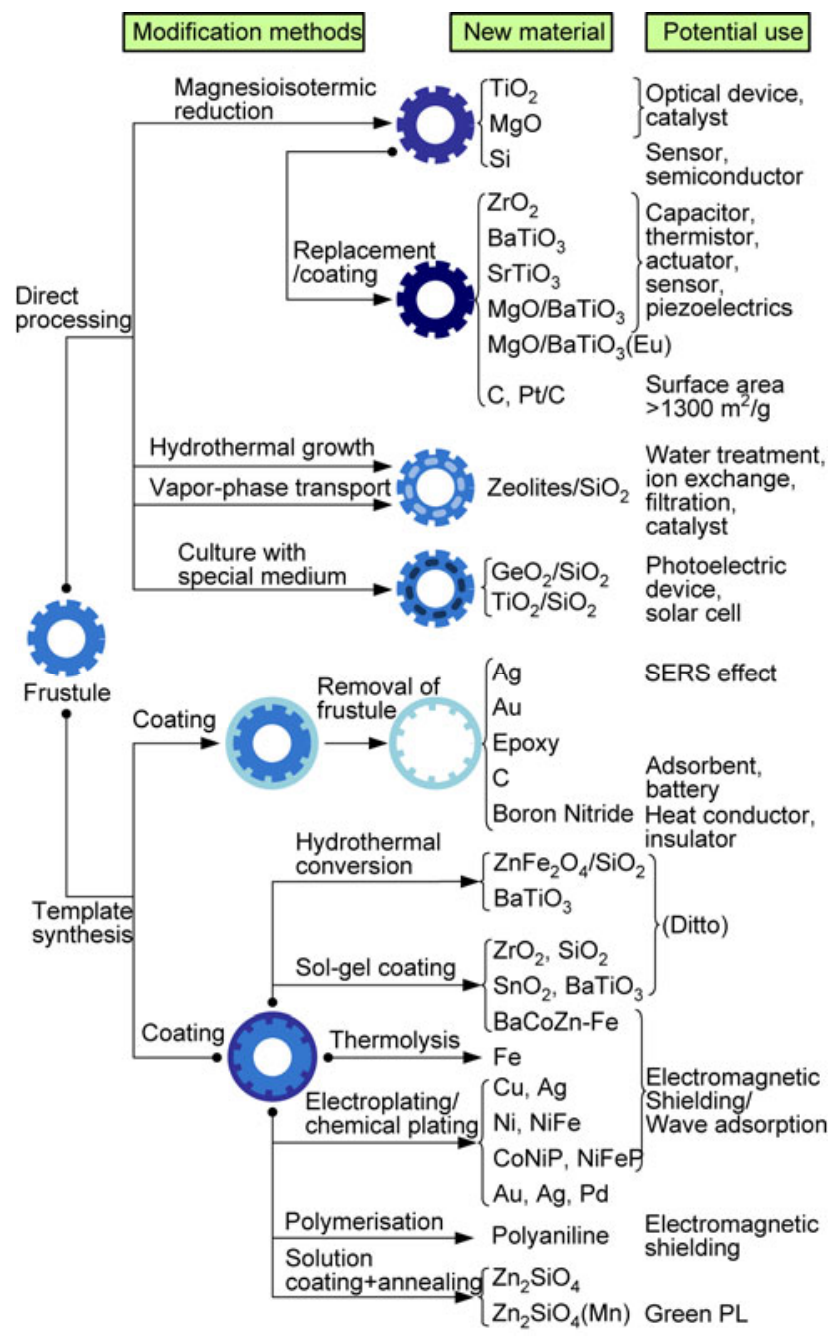

Figure 8 (Color online) Methods of material modification of a biosilica frustule. Revised on the basis of [21]. displacement reactions on $\mathrm{MgO}$ frustule substrates could produce new products, such as frustules composed of $\mathrm{ZrO}_{2}$ [63], $\mathrm{MgO} / \mathrm{BaTiO}_{3}, \mathrm{BaTiO}_{3}, \mathrm{MgO} / \mathrm{BaTiO}_{3}$ (coated with $\mathrm{Eu}^{3+}$ [64]), $\mathrm{SrTiO}_{3}$ [65], C, or Pt/C [66] (the expected properties or potential uses of these frustules are summarized in Figure 8). In addition, both hydrothermal growth and vapor-phase transport can produce zeolites/ $\mathrm{SiO}_{2}$ composite frustules [67,68], which have many uses such as molecular sieves and water/waste treatment $[69,70]$. Culture methods reported by Rorrer et al. [56,71] for the successful addition of $\mathrm{GeO}_{2}$ and $\mathrm{TiO}_{2}$ to biosilica frustules during the natural growth of a diatom have been described.

(ii) Frustules have been used as templates to obtain cast or composite frustule structures. Several cast structures of frustules were obtained by coating and subsequent removal of the frustules, which were composed of $\mathrm{Ag}$ [72], $\mathrm{Au}$ [73], epoxy [74], carbon [75,76], boron nitride [77] or $\mathrm{ZrO}_{2}$ [78]. Solution coating and subsequent thermal treatment could coat $\mathrm{ZnFe}_{2} \mathrm{O}_{4}$ [79], $\mathrm{Zn}_{2} \mathrm{SiO}_{4}$ (coated with $\mathrm{Mn}$ [80]) and $\mathrm{Ba}$ $\mathrm{TiO}_{3}[81,82]$ onto frustules. Electroless plating has been shown to be effective in coating metal ( $\mathrm{Au}, \mathrm{Ag}$ or $\mathrm{Pd}$ ) onto frustules [83]. Some composite frustules have new characteristics, for example, a polyaniline coated frustule has a certain degree of electrical conductivity [84]. We have used frustules of different shapes as templates to fabricate electromagnetic shielding or wave adsorbing particles (e.g. frustules coated with a layer of Ferrite [85,86], $\mathrm{Ag}[87], \mathrm{Cu}, \mathrm{Ni}$ Fe alloy [88], CoNiP, NiFeP or BaCoZn-ferrite [89]), and found that the frustule shape affects the electromagnetic properties of the coated frustules.

(iii) The replica method is precise at the nanoscale and could be used to make frustule structures with new and pure materials. Polydimethylsiloxane (PDMS) has been used to replicate the pore patterns of two centricae diatom frustules by a two-step replica method [90]. The PDMS replicas had the same multi-level pore structure as the original frustules and nanoscale precision of replication. The size error in the horizontal plane was less than $20 \mathrm{~nm}$, and the vertical size error was less than $50 \mathrm{~nm}$.

\subsection{Bonding technology for diatom frustules}

Making the frustules bond onto a substrate is a key problem in the fabrication of diatom-based devices. Several studies have reported success in modifying the surface of diatoms and substrates so as to encourage bonding with covalent bonds. Umemura et al. [38] used 3-Aminopropyltriethoxysilane (APES) to modify the mica substrate, and then the cells of pennate diatom would then readily attach to the modified surface during culturing. Wang et al. [91] used polyethylene with various electrical properties to separately modify the frustules and the substrate, and then the frustules can assemble and bind onto the area of the substrate having inverse electric charges.

We used silica bonding technology to facilitate the 
bonding of biosilica frustules onto a silicon-based substrate, such as common glass composed of $\mathrm{NaSiO}_{3} / \mathrm{SiO}_{2}$, quartz glass consisting of a pure $\mathrm{SiO}_{2}$, silicon wafer with a nanoscale surface oxide layer, and a PDMS substrate $[41,42,92,93]$. The mechanism of traditional silica bonding is to break the molecular structures at interfaces and then form $\mathrm{Si}-\mathrm{O}-\mathrm{Si}$ between the interfaces with the help of external energy. The external energy may be supplied in the form of pressure, heat, ultraviolet (UV) light or a catalyst. The diatom frustules are made up of $\mathrm{SiO}_{2}$, and so theoretically, they can be bonded with a silica substrate (or with each other) and form clean and firm Si-O-Si bonding. HF can be used as a catalyst (or etchant) in bonding frustules onto a common glass, quartz glass or silicon substrate. After immersing the frustules and substrate in 1\% HF for 1-3 min, the two interfaces were etched and unstable silanol groups generated. Then, the two interfaces were joined at $80^{\circ} \mathrm{C}$ for $3 \mathrm{~h}$ under a pressure of $0.6 \mathrm{MPa}$ to form $\mathrm{Si}-\mathrm{O}-\mathrm{Si}$ groups [42,92] (Figure 9(a)). Figure 9(c) shows the bonding interface of a frustule and quartz glass. Diatom frustules could be bonded with PDMS substrate under a more gentle condition (no pressure or heat). Exposing the sample to UV light with a wavelength $345 \mathrm{~nm}$ for $3 \mathrm{~h}$, converts some -OSi $\left(\mathrm{CH}_{3}\right)_{2} \mathrm{O}$ - groups on the surface of PDMS into $-\mathrm{O}_{4} \mathrm{Si}(\mathrm{OH})_{4-n^{-}}$ groups. The frustule and activated PDMS surface are attached (in $1 \mathrm{~min}$ ) and placed for $48 \mathrm{~h}$. During this period,
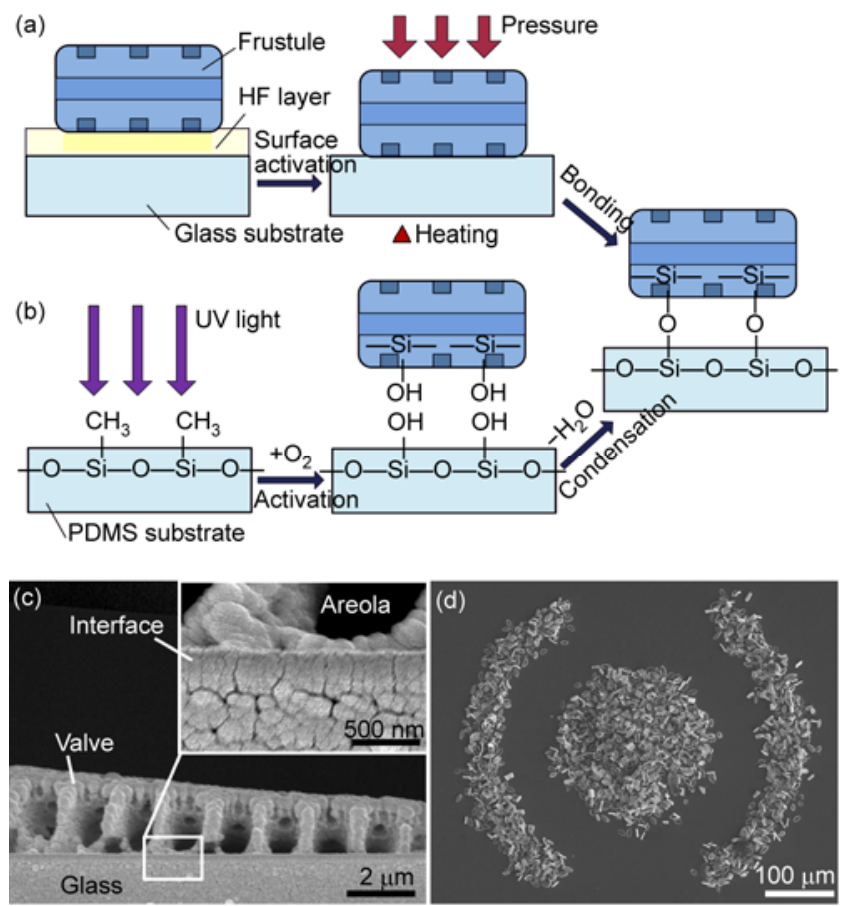

Figure 9 (Color online) Silica bonding between diatom frustules and silica-based substrate. (a) Schematic of bonding diatom frustules onto glass substrate assisted by HF activitation; (b) schematic of bonding diatom frustules onto PDMS substrate assisted by UV radiation; (c) interface between frustule (Coscinodiscus sp.) and quartz glass; (d) Nitzschia frustules bonded onto PDMS surface. the generated $\mathrm{Si}-\mathrm{OH}$ of PDMS will condense with the frustule $\mathrm{Si}-\mathrm{OH}$ and form $\mathrm{Si}-\mathrm{O}-\mathrm{Si}$ cross bonds [41,93] (Figure 9(b) and (d)). Both the above methods yield good bonding strength. When tested with AFM calibrated glass needle (for full test methods see [7,94]), a single frustule bonded onto glass/PDMS may be shown to withstand a shear force of more than $100 \mu \mathrm{N}$.

\subsection{Assembly technologies for diatom frustules}

Assembling diatom frustules into a 2D array or monolayer film is an important technique to improve the efficiency, function or throughput of diatom devices. The arrangement and bonding process of diatom frustules should be considered at the same time. Whilst the bonding process has been discussed in previous section, the arranging process will be dealt with under this section. Some possible methods for assembling microscale frustules include precise operation, self-assembly and using natural clusters of diatoms. A displacement precision of $0.1 \mu \mathrm{m}$ can be achieved using a micro-manipulator, which is ideal to precisely arrange diatom frustules on the 2D plane or 3D space. However, the efficiency is too low for batch operation and device fabrication. As pointed out in section 1.3, some diatoms are known to self-organize into clusters of various patterns. After fixing with $2.5 \%$ glutaraldehyde, these clusters could be arranged and fixed onto a substrate. Our lab attempted to culture long-chain clusters of diatom Nitzschia and in a long and narrow channel of PDMS chip, the cell clusters bonded to the channel bottom by UV-assisted bonding (see section 2.3), and the PDMS chip was well packed.

For arranging large quantities of frustules in 2D plane, the self-assembly and self-alignment methods [95,96] of the macroscale or mesoscale could be referenced. Reports about self-assembly of frustules are rare. Wang et al. [91] used an inkjet device to modify a glass surface so as to attract frustules to the modified region to form arrays. We have used lithography to study the patterning of frustules. As shown in Figure 10(a), a photo-resist film of $3 \mu \mathrm{m}$ was spin-coated onto a PDMS surface. After exposing and developing, some pits on the resist film showed patterns generated by the photo-mask, and thus the frustules could contact with patterned areas on PDMS surface. The subsequent bonding process and removal of resist film causes the frustules to fix onto PDMS in controlled patterns (Figure 10(c) and (d) are examples). For substrates composed of materials that cannot be easily bonded with frustules, an interlayer may be introduced between the frustules and substrate to fix the patterned frustules. For example, we fabricated a film of hot melt adhesive (HMA-the adhesive is composed of ethylene-vinyl acetate copolymer) on the glass surface as a bonding layer. The photo-resist was spin-coated on the HMA layer (Figure 10(b)). After the frustules formed patterns in pits of resist film, the glass substrate was heated to $110^{\circ} \mathrm{C}$ for $3 \mathrm{~min}$, at which temperature the HMA layer 
(a)
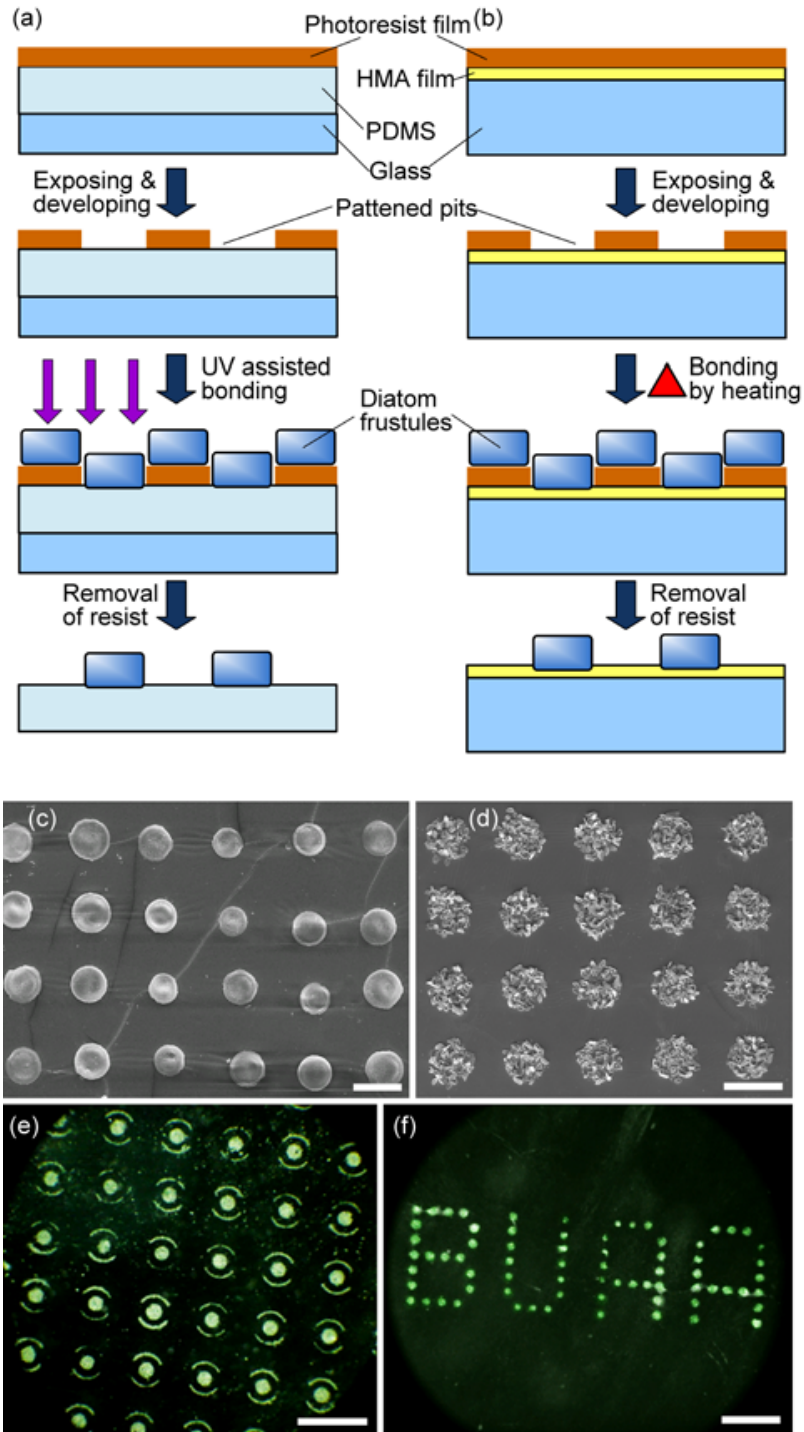

Figure 10 (Color online) Lithography-assisted arrangements of frustules on the substrate. (a) Schematic of arranging and bonding frustules onto PDMS substrate; (b) schematic of patterning and adhering frustules onto glass substrate; (c) array of Coscinodiscus valves bonded onto PDMS (SEM image, scale bar $50 \mu \mathrm{m}$ ); (d) array of Cymbella frustules bonded onto PDMS (SEM image, scale bar $100 \mu \mathrm{m}$ ); (e) eye patterns of Nitzschia frustules adhered onto PDMS (PL image under light microscope, scale bar $500 \mu \mathrm{m}$ ); (f) BUAA pattern of Cymbella frustules adhered onto glass substrate (PL image, scale bar $500 \mu \mathrm{m}$ ).

would fix the frustule patterns. Figure 10(e) and 10(f) show the PL image of frustule patterns adhering on the HMA layer after the removal of resist film, which indicates that the HMA material did not affect (or disturb) the optical property of frustules. Although new material was added between the frustule and substrate, the interlayer fixing methods are more practical in certain cases, because it allows the use of substrates of different materials-even flexible or elastic materials. The lithography-aided frustule assembly method has some advantages: the patterns can be designed in any shape and size, and the position accuracy and the arranging

efficiency are high.

Some researchers in Japan have proposed methods to fabricate micro-particles into compact monolayers or multilayers based on gravity, interfacial tension or magnetic force [97]. We used the floating assembly phenomenon to prepare a compact monolayer of Coscinodiscus valves and fix it on the substrates [94]. Some species of diatom Coscinodiscus sp. have convex valves with sieve pores distributed on the external surface. This kind of valve could float on water and assembly at the highest point of water (Figure 11(a)). The floating of the valves may due to the sieve pores, which prevent water from filling the areolae (Figure 11(c) is an estimate-the valve will sink in $1 \%$ HF solution in $1 \mathrm{~min}$, as the sieve pores enlarge). The buoyancy causes the valves to assemble at the highest point, and the attractive force existing between valves maintains the assembly state of valves. As shown in Figure 11(b), when valve A is moved, valve $B$ will move to valve $A$ if the distance between them is not more than $100 \mu \mathrm{m}$.

The buoyancy of the valves has several uses. First, after the water evaporated, the valves maintaining their assembly state can be fixed onto the substrate using a bonding method of the type described in section 2.3 (Figure 11(d)). A compact
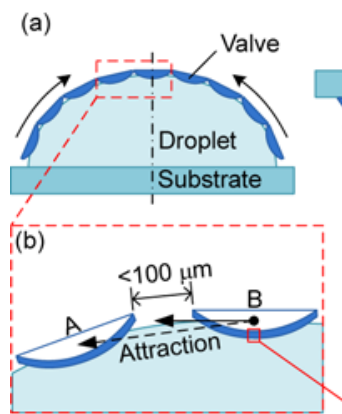

(d)
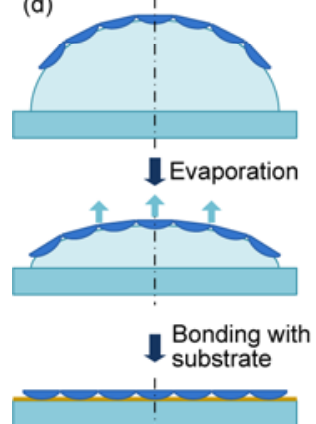

Monolayer/multilayer assembly

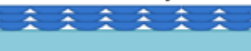

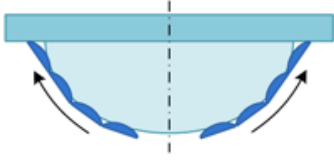

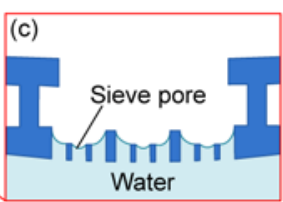

(f)
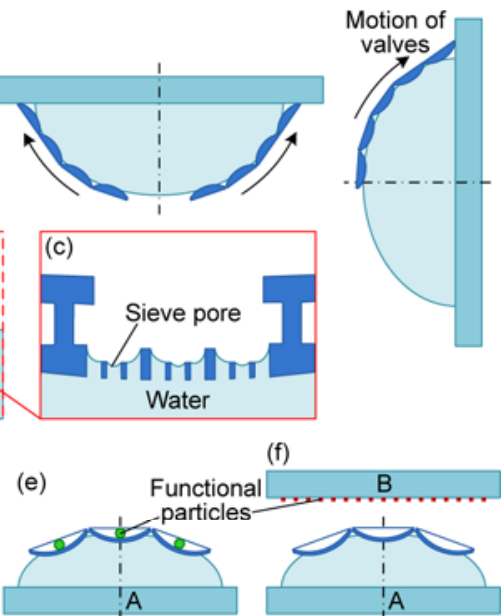

Particle fixing

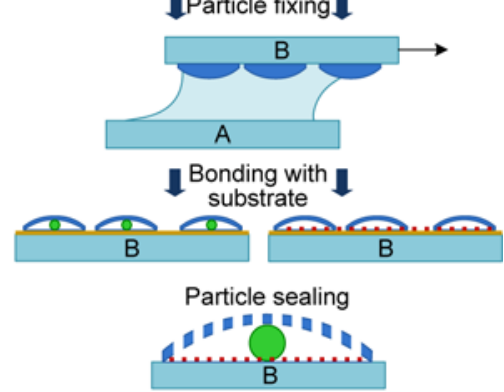

Figure 11 (Color online) Floating assembly of Coscinodiscus valves and some potential uses. (a) Motion of valves floating on water droplet; (b) attraction between valves which maintained their contact state; (c) a possible interface between the valve and water; (d) method of fabricating monolayer/multilayer of valves; (e) and (f) are methods of sealing particles with valves. 
monolayer of valves has been fixed onto a glass slide using HMA [94]. Second, valves with a convex lens shape can form an inner volume of about $1.5 \times 10^{4} \mu^{3}$ when attached onto a flat surface, which can be used to seal functional particles for filtration or optical use (e.g. light focusing). Figure 11(e) and (f) shows simple methods of particle sealing. Big particles (or small frustules modified with functional molecules) with sizes larger than sieve pores can be added to or scattered directly onto the valves; whilst particles smaller than sieve pores should be fixed onto the other substrate (B) in advance. The valves floating on the droplet of substrate A can be reversed and taken away by substrate B (see [98]). After bonding the large valves onto substrate $\mathrm{B}$, the particles were contained within chambers formed by the valves and substrate B. A biosensor model with similar structures has been proposed [16]: receptor molecules were sealed in the chamber of frustule, and thus small molecules may enter via the pores of frustule and bind to the receptors, eliciting a signal, while larger molecules disrupting the signal are prevented from entering the chamber.

For frustules which hardly float on water, octadecyltrichlorosilane (OTS) can be used to improve their hydrophobicity [99] and make them float and assemble. The rod shaped and flake shaped frustules/valves are most suited for this monolayer fabrication method.

\section{The outlook for diatom-based manufacturing technology}

Biological materials have been largely used in industrial products due to their fast reproduction rate, green and renewable nature, complex structures, and natural optimized functions. Diatom frustules possess several excellent functions and potential for micro- and nanoscale manufacturing.

\subsection{Potential of diatom frustules in device application}

Although diatoms are unicellular organisms, their frustules have evolved multiple physiological functions. In addition to protecting the interior of the cell [7], the frustules have the ability to adjust $\mathrm{pH}$ near cell surface for adsorbing $\mathrm{CO}_{2}$ [100] or to connect with other cells for survival and migration [101]. The pores of frustules also have some physiological functions. First, while providing the structural strength of the frustules, the pore chambers and pores help to control cell weight and allow the cells to float or migrate easily. Second, the pore matrix and the profile of the valves may form into a convex lens to gather light for photosynthesis [13]. Third, the sieve pores have a diameter between the size of nutrients and the size of bacteria [12], which help filter out harmful substances [102]. Moreover, the multilevel pores contribute to the large surface area of frustules, which help absorb nutrients from the surrounding environment.
Many industrial products utilize the natural functions of diatom frustules described earlier. For instance, construction materials made of diatomite can insulate heat and noise, and regulate humidity because of the outstanding pore volumes [103]. Diatomite filters can remove impurities and bacteria from water, and at the same time absorb metallic ions, fluoride ions and dye groups due to their surface electric properties [104]. However, the integration of these functions and properties into micro- or nano devices requires the comprehensive development and use of diatom processing technologies. Research on diatom-based biosensing devices and solar cells is discussed here to illustrate the importance of these new diatom processing technologies.

Many recent studies on biosensing devices use the photoluminescence (PL) properties of frustules. In 2005, De Stefano et al. [14] found that diatom frustules emit $500 \mathrm{~nm}$ wavelength blue light after being illuminated with an UV light of $325 \mathrm{~nm}$ wavelength, this is known as the PL phenomenon. The peak of the PL spectrum varies when the frustules are surrounded by different gases or vapors (e.g. $\mathrm{NO}_{2}$, ethanol or acetone). PL has attracted wide interest, and methods for enhancing the PL characteristics of frustules through special medium culture, thermal treatment and chemical modification have been reported $[57,61,105]$. Notably, Bao et al. [61] modified the original biosilica frustule into a nanocrystalline $\mathrm{Si}$ material whilst maintaining the original frustule structure. The absorbability and PL characteristics of modified frustules have an enhancement: PL spectrum sensitive to gases at $1 \mathrm{ppm}$. In 2009, Gale et al. [25] found that PL can be affected by the biomass attached to the frustules, and used frustules for protein detection a year after Townley et al. [24] first bound proteins onto frustules. With the technique of protein binding, Lin et al. [27] used frustules with uniform pores as biocarriers for electrochemical detection. Compared with other 3D carriers (e.g. porous alumina), the frustule-based carrier performed with better detection sensitivity and linearity. We have explored the potential of diatom in biochip or microfluidic chip detection (using fluorescence detection), which employed the techniques of protein binding and frustule arranging/bonding. There are several advantages of the use of frustules in optical detection (Figure 12(a)). First, the large surface and porous structure of the frustule allow the antibody to be bound to the outer surface, inner surface and pores, and all the optical signals of antibody can be still discerned due to the transparency of the frustule [106,107]. Second, a frustule region with a high antibody density can enhance the contact rate of both antibody and antigen, and thus improve the detection sensitivity and signal intensity (a triple signal intensity from the frustule system is detected compared with a glass equivalent). Third, the porous structure of the frustule allows the antigens to freely contact with the antibodies by "surface flow" or "flow-through" motion, reducing the hybridization time. These examples show the potential of frustules in biosensing devices, whilst stressing 
on the need to develop improved processing technology.

Recently, diatoms have been proposed for use in solar cells, batteries, or electroluminescent devices by Rorrer's research group [19]. Dye-sensitized solar cells (DSC) is a low cost photovoltaic device [108] with a solar-current conversion efficiency of about $12 \%$. DSC works as follows. The ruthenium based dye particles are bound to a crystalline anatase $\mathrm{TiO}_{2}$ film (forming the photoanode), which are immersed in electrolyte. When irradiated by sunlight, the dye releases electrons to the $\mathrm{TiO}_{2}$ film and forms electron hole pairs. The electrons pass through the $\mathrm{TiO}_{2}$ layer, conductive glass (FTO-glass), the appliance or load and back to the electrolyte. The electrolyte releases electrons to fill the electron hole in the dye. Jeffryes et al. [71] inserted $\mathrm{TiO}_{2}$ to frustules by culture, and attached the composite frustules to the dye- $\mathrm{TiO}_{2}$ layer (Figure 12(b)). The transparent frustule will not block the penetration of photons; and the light scattering, light reflection and light focusing caused by pores of frustules all help to direct photons to the dye [109,110]. Enhancement of photonic capture results in a thinner photoanode layer which decreases the electron diffusion distance, increases the efficiency and reduces the fabrication cost. The effectiveness of the $\mathrm{TiO}_{2}$-frustule layer can be
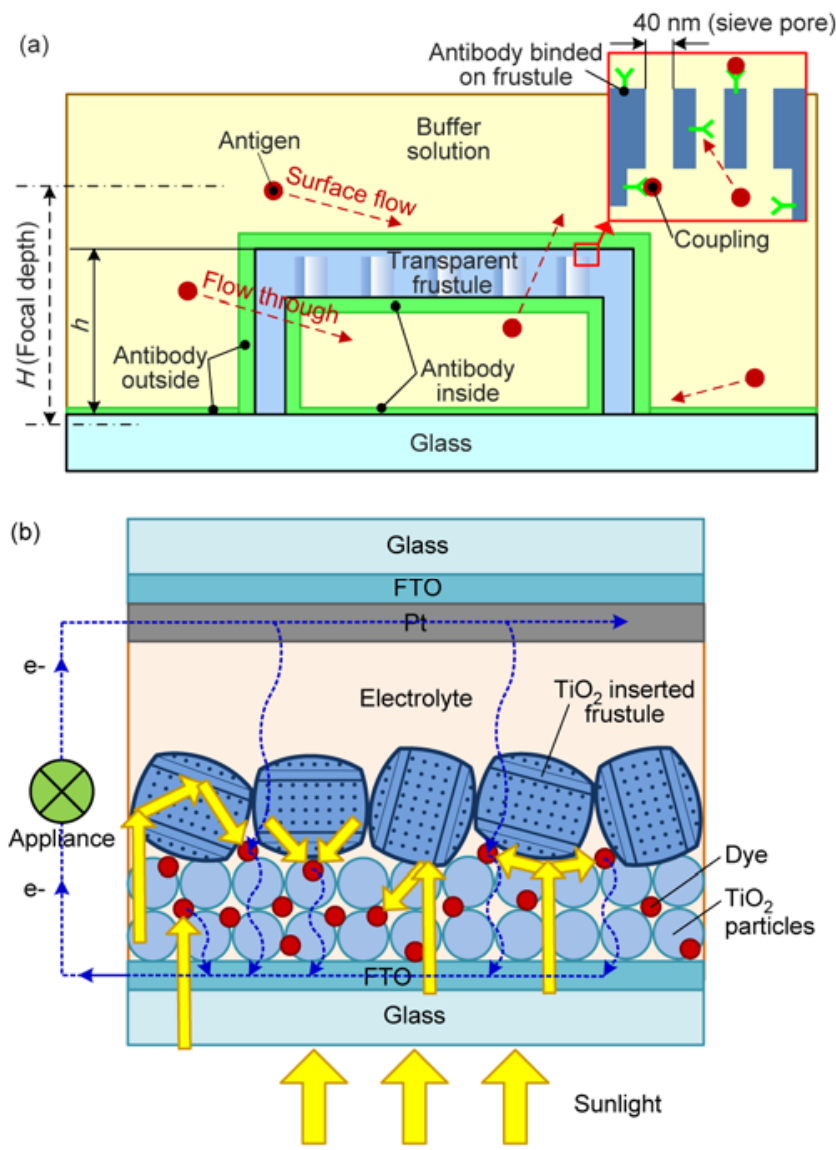

Figure 12 (Color online) Schematics of some diatom based devices. (a) Optical bio-detection using frustules as a biocarrier; (b) a diatom based DCS device (revised on the basis of [19]). improved, because the quality of titanium inserted into frustule is low $\left(4.9 \mathrm{~g} \mathrm{TiO}_{2} / 100 \mathrm{~g} \mathrm{SiO}_{2}\right)$ and the $\mathrm{TiO}_{2}$ is mostly distributed near the pores. In a subsequent study, Jeffryes et al. [111] used a deposition method to fabricate composite frustules with a uniform $\mathrm{TiO}_{2}$ coating layer (1.13 $\mathrm{g} \mathrm{TiO}_{2} / 1 \mathrm{~g} \mathrm{SiO}_{2}$ ). The addition of the composite frustule in the photoanode improves the efficiency by $3.7 \%$. Thus it can be seen that new diatom processing methods can improve the performance of diatom devices.

\subsection{The evolution of diatom processing technologies}

In diatom processing, better methods for culturing, extraction and modification need to be identified. First, we should promote large scale culturing and extraction techniques for obtaining industrial quantities of frustule structures [112]. Thousands of species of diatoms could be obtained from natural waters (or diatom culture collections) for studies. However, no more than 30 species of diatoms have been found of use in processing technology and device application. Often the source of the frustules is diatomite, the advantages of which include low cost and a high yield of frustules. One disadvantage of diatomite that, as compared with fresh frustules collected from living cells, is damage to the cribellum (or sieve plate) and the lower surface area. Thus, better culturing techniques need to be developed to actually realize the potential from frustule diversity in device research. Second, techniques for selecting matching frustules should be promoted. After diatom fissiparity, one can identify frustules of different sizes. For example marine Coscinodiscus sp., although the micropores are of the same size, their diameters range from 60 to $100 \mu \mathrm{m}$, in accordance with the normal distribution. Current research uses the properties of a single frustule or considers the micropores en mass. However, when diatom devices are to be produced on a mass scale, frustule assembling and device stability depend to a certain degree on the uniform size of frustules. That is why size selection and structure selection methods are in great need. Third, the biological functions, growth methods, and structural, mechanical, physical and chemical properties of diatom frustules should be understood more completely and deeply, which will promote better processing methods. In addition, material modification methods are important for diatom applications. Controlling and using the functions of new materials is also important. For replication methods, nanoscale replica precision has been realized. In the next step, rapid and large area replication techniques and structure magnifying/reducing replication technique are required.

Assembling and bonding techniques are important for device manufacturing. Bonding problems mainly arise from frustule-substrate and frustule-frustule bonding. Some existing $\mathrm{Si}-\mathrm{O}-\mathrm{Si}$ bonding technologies can be tried, but high pressure and temperature $\left(>600^{\circ} \mathrm{C}\right)$ should be avoided. The use of an interlayer simplifies the bonding process but the 
thickness of the interlayer must be controlled (to nanoscale at best) to avoid blockage of the micropores or decline in properties of the surface area. Possible materials for the interlayer include hot melt adhesive, photosensitive resins, and spin on glass. New methods may be exploited for bonding frustules onto different materials, such as metal plates, organic material products, or living bodies. Biosilica possesses good biocompatibility, and thus frustules may be fixed to the body of creatures without allergy and rejection, exploiting the potential of frustules in biodetection and tissue engineering. To overcome assembling problems, the goal is to develop micro- or nanoporous devices composed of $2 \mathrm{D}$ or $3 \mathrm{D}$ assembled frustules. When such assembling technologies exist, numerous micro- or nanoporous products composed of frustules may appear in future, such as diatom clothes with multiple functions (air conditioning, humidity adjusting, and light warming), multi-channel fuel cells, integrated circuits, processors using light to perform logical operations, etc.

As a new functional material, diatom frustules have attracted attentions from many broad disciplines (biology, material, micro- and nanotechnology, chemistry, machinery, medical science.). In the past decade, the scientific and technological fruits from the use of diatom frustules have been used in medical science, micro- and nano-manufacturing, optomechatronics devices, semiconductors, computer science. A great measure of commercial interest has been achieved in those fields. In the foreword of Gordon's monograph "Diatom nanotechnology: special issue", seven current or prospective applications of diatom nanotechnology were described [113]. Most research is still laboratory-based. This review mainly summarizes certain newly reported methods of diatom processing and discusses possible frustule processing methods for device application. The aim of this paper is to support and encourage bio-manufacturing technology in our country.

This work was supported by the National Natural Science Foundation of China (50805005, 51075020), the National High Technology Research and Development Program of China (2009AA043804), and the Doctoral Candidate Academic Newcomer Award of the Ministry of Education of China. The authors expresses their great thanks to the Freshwater Algae Culture Collection of the Institute of Hydrobiology (FACHB-Collection) of Chinese Academy of Sciences, Prof. Yahui Gao and Dr. Lin Sun of the Diatom Laboratory of Xiamen University, the Capitalbio corporation, Linjiang Silite Diatomite Corporation, Shengzhou Huali Diatomite Corporation, and Mingli Chen, Aobo Li, Wenqiang Zhang, and Yuanyue Li for help and suggestions.

1 Dai Z, Tong J, Ren L. Researches and developments of biomimetics in tribology. Chin Sci Bull, 2006, 51: 2681-2689

2 Zhang D, Cai J, Li X, et al. Bioforming methods of bionic manufacturing (in Chinese). J Mech Eng, 2010, 45: 88-92

3 Li X, Li Y, Cai J, et al. Metallization of bacteria cells. Sci China Ser E: Technol Sci, 2003, 46: 161-167

4 Zhang D, Li Y, Han X, et al. High-precision bio-replication of synthetic drag reduction shark skin. Chin Sci Bull, 2011, 56: 938-944

5 Han X, Zhang D. Study on the micro-replication of shark skin. Sci
China Ser E: Technol Sci, 2008, 51: 890-896

6 Dickerson M B, Sandhage K H, Naik R R. Protein- and peptide- directed syntheses of inorganic materials. Chem Rev, 2008, 108: 49354978

7 Hamm C E, Merkel R, Springer O, et al. Architecture and material properties of diatom shells provide effective mechanical protection. Nature, 2003, 421: 841-843

8 Losic D, Short K, Mitchell J G, et al. AFM nanoindentations of diatom biosilica surfaces. Langmuir, 2007, 23: 5014-5021

9 Qi Y, Li J. Chinese Freshwater Algae Chapter 10: Bacillariophyta (in Chinese). Beijing: Science Press, 2004

10 Qian S, Liu D, Sun J. Phylology Chapter 9: Bacillariophyta (in Chinese). Qingdao: Qingdao Ocean University Press, 2005

11 Bozarth A, Maier U G, Zauner S. Diatoms in biotechnology: Modern tools and applications. Appl Microbiol Biotechnol, 2009, 82: 195201

12 Losic D, Rosengarten G, Mitchell J G, et al. Pore architecture of diatom frustules: Potential nanostructured membranes for molecular and particle separations. J Nanosci Nanotechnol, 2006, 6: 982-989

13 De Stefano L, Rea I, Rendina I, et al. Lensless light focusing with the centric marine diatom Coscinodiscus walesii. Opt Express, 2007, 15: 18082-18088

14 De Stefano L, Rendina I, De Stefano M, et al. Marine diatoms as optical chemical sensors. Appl Phys Lett, 2005, 87: 233902. 1-3

15 Fuhrmann T, Landwehr S, El Rharbi-Kucki M, et al. Diatoms as living photonic crystals. Appl Phys B, 2004, 78: 257-260

16 Parkinson J, Gordon R. Beyond micromachining: The potential of diatoms. Trends Biotechnol, 1999, 17: 190-196

17 Gordon R, Losic D, Tiffany M A, et al. The glass menagerie: Diatoms for novel applications in nanotechnology. Trends Biotechnol, 2009, 27: 116-127

18 Yang W, Lopez P J, Rosengarten G. Diatoms: Self assembled silica nanostructures, and templates for bio/chemical sensors and biomimetic membranes. Analyst, 2011, 136: 42-53

19 Jeffryes C, Campbell J, Li H, et al. The potential of diatom nanobiotechnology for applications in solar cells, batteries, and electroluminescent devices. Energy Environ Sci, 2011, 4: 3930-3941

20 Gordon R, Sterrenburg F A S, Sandhage K H. Diatom Nanotechnology: Special issue. New York: American Scientific Publishers, 2005

21 Losic D, Mitchell J G, Voelcker N H. Diatomaceous lessons in nanotechnology and advanced materials. Adv Mater, 2009, 21: 2947-2958

22 Lettieri S, Setaro A, De Stefano L, et al. The gas-detection properties of light-emitting diatoms. Adv Funct Mater, 2008, 18: 1257-1264

23 Losic D, Yu Y, Aw M S, et al. Surface functionalisation of diatoms with dopamine modified iron-oxide nanoparticles: Toward magnetically guided drug microcarriers with biologically derived morphologies. Chem Commun, 2010, 46: 6323-6325

24 Townley H E, Parker A R, White-Cooper H. Exploitation of diatom frustules for nanotechnology: Tethering active biomolecules. Adv Funct Mater, 2008, 18: 369-374

25 Gale D K, Gutu T, Jiao J, et al. Photoluminescence detection of biomolecules by antibody-functionalized diatom biosilica. Adv Funct Mater, 2009, 19: 926-933

26 De Stefano L, Rotiroti L, De Stefano M, et al. Marine diatoms as optical biosensors. Biosens Bioelectron, 2009, 24: 1580-1584

27 Lin K-C, Kunduru V, Bothara M, et al. Biogenic nanoporous silica-based sensor for enhanced electrochemical detection of cardiovascular biomarkers proteins. Biosens Bioelectron, 2010, 25: 23362342

28 Kroth P. Molecular Biology and the Biotechnological Potential of Diatoms Transgenic Microalgae as Green Cell Factories. New York: Springer, 2007

29 Hildebrand M. Biological processing of nanostructured silica in diatoms. Prog Org Coat, 2003, 47: 256-266

30 Martin-Jézéquel V, Hildebrand M, Brzezinski M A. Silicon metabolism in diatoms: Implications for growth. J Phycol, 2000, 36: 821840

31 Nassif N, Livage J. From diatoms to silica-based biohybrids. Chem Soc Rev, 2011, 40: 849-859 
32 Ramachandra T V, Mahapatra D M, Karthick B, et al. Milking diatoms for sustainable energy: Biochemical engineering versus gasolinesecreting diatom solar panels. Ind Eng Chem Res, 2009, 48: 87698788

33 Brayner R, Couté A, Livage J, et al. Micro-algal biosensors. Anal Bioanal Chem, 2011, 401: 581-597

34 Neethirajan S, Gordon R, Wang L. Potential of silica bodies (phytoliths) for nanotechnology. Trends Biotechnol, 2009, 27: 461-467

35 Round F E, Crawford R M, Mann D G. The Diatoms: Biology and Morphology of the Genera. Cambridge: Cambridge University Press, 1990

36 Fan T X, Chow S K, Zhang D. Biomorphic mineralization: From biology to materials. Prog Mater Sci, 2009, 54: 542-659

37 Grachev M A, Annenkov V V, Likhoshway Y V. Silicon nanotechnologies of pigmented heterokonts. BioEssays, 2008, 30: 328-337

38 Umemura K, Noguchi Y, Ichinose T, et al. Diatom cells grown and baked on a functionalized mica surface. J Biol Phys, 2008, 34: 189196

39 Zhang D Y, Wang Y, Zhang W Q, et al. Enlargement of diatom frustules pores by hydrofluoric acid etching at room temperature. J Mater Sci, 2011, 46: 5665-5671

40 Crawford S A, Chiovitti A, Pickett-Heaps J, et al. Micromorphogenesis during diatom wall formation produces siliceous nanostructures with different properties. J Phycol, 2009, 45: 1353-1362

41 Wang Y, Pan J, Cai J, et al. Assembling and patterning of diatom frustules onto PDMS substrates using photo-assisted chemical bonding. Chem Lett, 2011, 40: 1354-1356

42 Zhang D, Cai J, Pan J, et al. Bonding method of diatom shell or kieselguhr and glass. PRC Patent, CN 101786799-A, 2010-7-28

43 Matthias S, Muller F. Asymmetric pores in a silicon membrane acting as massively parallel brownian ratchets. Nature, 2003, 424: 53-57

44 Zhang D Y, Wang Y, Pan J F, et al. Separation of diatom valves and girdle bands from Coscinodiscus diatomite by settling method. J Mater Sci, 2010, 45: 5736-5741

45 Zhang D, Cai J, Wang Y, et al. Method for separating and extracting shell pieces and clitellum from kieselguhr or diatoms. PRC Patent, CN 101792145-A, 2010-8-4

46 Losic D, Triani G, Evans P J, et al. Controlled pore structure modification of diatoms by atomic layer deposition of $\mathrm{TiO}_{2}$. J Mater Chem, 2006, 16: 4029-4034

47 Crawford S A, Higgins M J, Mulvaney P, et al. Nanostructure of the diatom frustule as revealed by atomic force and scanning electron microscopy. J Phycol, 2001, 37: 543-554

48 Hildebrand M, Volcani B E, Gassmann W, et al. A gene family of silicon transporters. Nature, 1997, 385: 688-689

49 Sumper M. A Phase Separation model for the nanopatterning of diatom biosilica. Science, 2002, 295: 2430-2433

50 Kröger N, Deutzmann R, Sumper M. Polycationic peptides from diatom biosilica that direct silica nanosphere formation. Science, 1999, 286: $1129-1132$

51 Sumper M, Kroger N. Silica formation in diatoms: The function of long-chain polyamines and silaffins. J Mater Chem, 2004, 14: 2059_ 2065

52 Kröger N, Lorenz S, Brunner E, et al. Self-assembly of highly phosphorylated silaffins and their function in biosilica morphogenesis. Science, 2002, 298: 584-586

53 Telford R J, Vandvik V, Birks H J B. How many freshwater diatoms are $\mathrm{pH}$ specialists? A response to Pither \& Aarssen (2005). Ecol Lett, 2006, 9: E1-E5

54 Vrieling E, Sun Q, Tian M, et al. Salinity-dependent diatom biosilicification implies an important role of external ionic strength. Proc Natl Acad Sci USA, 2007, 104: 10441-10446

55 Townley H E, Woon K L, Payne F P, et al. Modification of the physical and optical properties of the frustule of the diatom Coscinodiscus wailesii by nickel sulfate. Nanotechnology, 2007, 18: 295101.1295101.5

56 Jeffryes C, Solanki R, Rangineni Y, et al. Electroluminescence and photoluminescence from nanostructured diatom frustules containing metabolically inserted germanium. Adv Mater, 2008, 20: 2633-2637
57 Jeffryes C, Gutu, T, Jiao J, et al. Two-stage photobioreactor process for the metabolic insertion of nanostructured germanium into the silica microstructure of the diatom Pinnularia sp. Mater Sci Eng C, 2008, 28: 107-118

58 Poulsen N, Chesley P M, Kroger N. Molecular genetic manipulation of the diatom Thalassiosira pseudonana (Bacillariophyceae). J Phycol, 2006, 42: 1059-1065

59 Cai Y, Allan S M, Sandhage K H. Three-dimensional magnesiabased nanocrystal assemblies via low-temperature magnesiothermic reaction of diatom microshells. J Am Ceram Soc, 2005, 88: 2005-2010

60 Lee S J, Huang C H, Shian S, et al. Rapid hydrolysis of organophosphorous esters induced by nanostructured, fluorine-doped titania replicas of diatom frustules. J Am Ceram Soc, 2007, 90: 1632-1636

61 Bao Z, Weatherspoon M R, Shian S, et al. Chemical reduction of three-dimensional silica micro-assemblies into microporous silicon replicas. Nature, 2007, 446: 172-175

62 Sandhage K H, Dickerson M B, Huseman P M, et al. Novel, bioclastic route to self-assembled, 3D, chemically tailored meso/nanostructures: Shape-preserving reactive conversion of biosilica (diatom) microshells. Adv Mater, 2002, 14: 429-433

63 Shian S, Cai Y, Weatherspoon M R, et al. Three-dimensional assemblies of zirconia nanocrystals via shape-preserving reactive conversion of diatom microshells. J Am Ceram Soc, 2006, 89: 694-698

64 Weatherspoon M R, Haluska M S, Cai Y, et al. Phosphor microparticles of controlled three-dimensional shape from phytoplankton. J Electrochem Soc, 2006, 153: H34-H37

65 Dudley S, Kalem T, Akinc M. Conversion of $\mathrm{SiO}_{2}$ diatom frustules to $\mathrm{BaTiO}_{3}$ and $\mathrm{SrTiO}_{3}$. J Am Ceram Soc, 2006, 89: 2434-2439

66 Bao Z, Song M-K, Davis S C, et al. High surface area, micro/mesoporous carbon particles with selectable 3-D biogenic morphologies for tailored catalysis, filtration, or adsorption. Energy Environ Sci, 2011, 4: 3980-3984

67 Anderson M W, Holmes S M, Hanif N, et al. Hierarchical pore structures through diatom zeolitization. Angew Chem Int Ed, 2000, 39: 2707-2710

68 Anderson M W, Holmes S M, Mann R, et al. Zeolitisation of diatoms. J Nanosci Nanotechnol, 2005, 5: 92-95

69 Hernandez-Ramirez O, Hill P I, Doocey D J, et al. Removal and immobilisation of cobalt ions by a novel, hierarchically structured, diatomite/zeolite Y composite. J Mater Chem, 2007, 17: 1804-1808

70 Sanhueza V, Kelm U, Cid R, et al. Synthesis of ZSM-5 from diatomite: A case of zeolite synthesis from a natural material. J Chem Technol Biotechnol, 2004, 79: 686-690

71 Jeffryes C, Gutu T, Jiao J, et al. Metabolic insertion of nanostructured $\mathrm{TiO}_{2}$ into the patterned biosilica of the diatom Pinnularia sp by a twostage bioreactor cultivation process. ACS Nano, 2008, 2: 2103-2112

72 Payne E K, Rosi N L, Xue C, et al. Sacrificial biological templates for the formation of nanostructured metallic microshells. Angew Chem Int Ed, 2005, 44: 5064-5067

73 Yu Y, Addai-Mensah J, Losic D. Synthesis of self-supporting gold microstructures with three-dimensional morphologies by direct replication of diatom templates. Langmuir, 2010, 26: 14068-14072

74 Gaddis C S, Sandhage K H. Freestanding microscale 3D polymeric structures with biologically-derived shapes and nanoscale features. J Mater Res, 2004, 19: 2541-2545

75 Holmes S M, Graniel-Garcia B E, Foran P, et al. A novel porous carbon based on diatomaceous earth. Chem Commun, 2006, 2662-2663

76 Cai X, Zhu G, Zhang W, et al. Diatom-templated synthesis of ordered meso/macroporous hierarchical materials. Eur J Inorg Chem, 2006: 3641-3645

77 Kusari U, Bao Z, Cai Y, et al. Formation of nanostructured, nanocrystalline boron nitride microparticles with diatom-derived 3-D shapes. Chem Commun, 2007, 1177-1179

78 Zhao J, Gaddis C S, Cai Y, et al. Free-standing microscale structures of nanocrystalline zirconia with biologically replicable three-dimensional shapes. J Mater Res, 2005, 20: 282-287

79 Liu Z, Fan T, Zhou H, et al. Synthesis of $\mathrm{ZnFe}_{2} \mathrm{O}_{4} / \mathrm{SiO}_{2}$ composites derived from a diatomite template. Bioinspi Biomim, 2007, 2: 30

80 Lee D H, Gutu T, Jeffryes C, et al. Nanofabrication of green lumi- 
nescent $\mathrm{Zn}_{2} \mathrm{SiO}_{4}$ :Mn using biogenic silica. Electrochem Solid-State Lett, 2007, 10: K13-K16

81 Weatherspoon M R, Allan S M, Hunt E, et al. Sol-gel synthesis on self-replicating single-cell scaffolds: Applying complex chemistries to nature's 3-D nanostructured templates. Chem Commun, 2005, $651-653$

82 Ernst E M, Church B C, Gaddis C S, et al. Enhanced hydrothermal conversion of surfactant-modified diatom microshells into barium titanate replicas. J Mater Res, 2007, 22: 1121-1127

83 Bao Z H, Ernst E M, Yoo S, et al. Syntheses of porous self-supporting metal-nanoparticle assemblies with 3D morphologies inherited from biosilica templates (diatom Frustules). Adv Mater, 2009, 21: 474-478

84 Li X W, Bian C Q, Chen W, et al. Polyaniline on surface modification of diatomite: A novel way to obtain conducting diatomite fillers. Appl Surf Sci, 2003, 207: 378-383

85 Zhang D, Zhang W, Cai J. Magnetization of microorganism cells by thermal decomposition method. Sci China Technol Sci, 2011, 54: 1275-1280

86 Zhang W, Zhang D, Cai J. Fabrication of flake-shaped core-shell micro particles by way of thermal decomposition of pentacarbonyl iron on diatomite surface. Adv Eng Mater, 2011: 730-733

87 Lan M, Zhang D, Cai J, et al. Electroless plating of silver on microorganism cells. Adv Mater Res, 2011: 531-535

88 Cai J, Zhang D Y, Lan M M, et al. Research on magnetic metallization of microorganism cells using electroplating technique. Sci China Technol Sci, 2011, 54: 1525-1531

89 Zhang D, Zhang W, Cai J. Fabrication and electromagnetic properties of flake ferrite particles based on diatomite. J Magn Magn Mater, 2011, 323: 2305-2309

90 Losic D, Mitchell J G, Lal R, et al. Rapid fabrication of micro- and nanoscale patterns by replica molding from diatom biosilica. Adv Funct Mater, 2007, 17: 2439-2446

91 Wang W, Gutu T, Gale D K, et al. Self-assembly of nanostructured diatom microshells into patterned arrays assisted by polyelectrolyte multilayer deposition and inkjet printing. J Am Chem Soc, 2009, 131: 4178-4179

92 Zhang D, Pan J, Cai J, et al. Hydrofluoric acid-assisted bonding of diatoms with $\mathrm{SiO}_{2}$-based substrates for microsystem application. J Micromech Microeng, 2012, 22: 35021-35029

93 Cai J, Wang Y, Zhang D, et al. A method of assembling and patterning diatom frustules onto PDMS substrates. PRC Patent, CN 201110326629. 1, 2011-10-25

94 Wang Y, Pan J, Cai J, et al. Floating assembly of diatom Coscinodiscus sp microshells. Biochem Biophys Res Commun, 2012, 420: 1-5

95 George M W, Grzybowski B. Self-assembly at all scales. Science, 2002, 295: 2418-2421

96 Whitesides G M, Boncheva M. Beyond molecules: Self-assembly of mesoscopic and macroscopic components. Proc Natl Acad Sci USA, 2002, 99: 4769-4774

97 Nagayama K. Science of Self-Aasembly. Tokyo: Maruzen Co., Ltd,
1997

98 Srinivasan U, Liepmann D, Howe R T. Microstructure to substrate self-assembly using capillary forces. J Microelectromech Syst, 2001, 10: $17-24$

99 Kulkarni S A, Ogale S B, Vijayamohanan K P. Tuning the hydrophobic properties of silica particles by surface silanization using mixed self-assembled monolayers. J Colloid Interface Sci, 2008, 318: 372-379

100 Milligan A J, Morel F M M. A proton buffering role for silica in diatoms. Science, 2002, 297: 1848-1850

101 De Stefano M, De Stefano L, Congestri R. Functional morphology of micro- and nanostructures in two distinct diatom frustules. Superlattices Microstruct, 2009, 46: 64-68

102 Raven J A, Waite A M. The evolution of silicification in diatoms: Inescapable sinking and sinking as escape? New Phytol, 2004, 162: 45-61

103 Zhang F. Processing and Application of Diatomite (in Chinese). Beijing: Chemical Industry Press, 2006

104 Lin J. Study on preparation, characterization and dyes adsorption properties of diatomite-based adsorbent (in Chinese). Doctoral Dissertation. Hangzhou: Zhejiang University, 2007

105 Umemura K, Noguchi Y, Ichinose T, et al. Morphology and physical-chemical properties of baked nanoporous frustules. J Nanosci Nanotechnol, 2010, 10: 5220-5224

106 Wang Y, Zhang D, Pan J, et al. Key factors influencing the optical detection of biomolecules by their evaporative assembly on diatom frustules. J Mater Sci, 2012, doi: 10.1007/s10853-10012-1655410854

107 Pan J, Cai J, Zhang D, et al. Micro-arraying of nanostructured diatom microshells on glass substrate using ethylene-vinyl acetate copolymer and photolithography technology for fluorescence spectroscopy application. Physica E, 2012, doi: 10.1016/j.physe.2012. 1003.1032

108 Grätzel M. Dye-sensitized solar cells. J Photochem Photobiol C, 2003, 4: $145-153$

109 Park K H, Gu H B, Jin E M, et al. Using hybrid silica-conjugated $\mathrm{TiO}_{2}$ nanostructures to enhance the efficiency of dye-sensitized solar cells. Electrochim Acta, 2010, 55: 5499-5505

110 Ito S, Murakami T N, Comte P, et al. Fabrication of thin film dye sensitized solar cells with solar to electric power conversion efficiency over 10\%. Thin Solid Films, 2008, 516: 4613-4619

111 Jeffryes C, Gutu T, Jiao J, et al. Peptide-mediated deposition of nanostructured $\mathrm{TiO}_{2}$ into the periodic structure of diatom biosilica. $\mathrm{J}$ Mater Res, 2008, 23: 3255-3262

112 Wang Y, Zhang D, Cai J, et al. Biosilica structures obtained from Nitzschia, Ditylum, Skeletonema, and Coscinodiscus diatom by a filtration-aided acid cleaning method. Appl Microbiol Biotechnol, 2012, 95: $1165-1178$

113 Gordon R. Preface to the Diatom Nanotechnology Special Issue. J Nanosci Nanotechnol, 2005, 5: 1-4

Open Access This article is distributed under the terms of the Creative Commons Attribution License which permits any use, distribution, and reproduction in any medium, provided the original author(s) and source are credited. 